\title{
The Reasons and Evaluations of Mergers and Acquisitions
}

\author{
Bader Almazur $^{1}$, Augustine C. Arize ${ }^{2}$, Giuliana Campanelli Andreopoulos ${ }^{1}, \operatorname{John}_{\text {Malindretos }}^{3} \&$ Alex Panayides ${ }^{1}$ \\ ${ }^{1}$ Department of Economics and Finance, Cotsakos College of Business, William Paterson University, USA \\ ${ }^{2}$ Regents Professor, Department of Economics and Finance, College of Business, Texas A\&M University-Commerce, \\ USA \\ ${ }^{3}$ Department of Economics, Finance and Global Business, Cotsakos College of Business, William Paterson University, \\ USA
}

Correspondence: John Malindretos, Department of Economics, Finance and Global Business, Cotsakos College of Business, William Paterson University, USA

Received: July 21, 2017

doi:10.5430/afr.v7n3p211
Accepted: June 15, 2018

Online Published: July 9, 2018

\begin{abstract}
This paper looks at mergers and acquisitions of companies. Specifically, the paper reviews the backdrop of mergers and takeovers, their history, types and reasons, prospects of productivity, synergy, growth, reduction of risk, and associated challenges. The analysis is conducted in the light of mergers and acquisitions in Europe and the United States, which are hotbeds of M\&A activities. Through the selected cases, different pre- and post-merger situations are carefully analyzed. The findings are presented in both quantitative and qualitative forms, and the discussion elucidates the findings in light of existing literature on mergers and acquisitions. The paper concludes with solutions to some of the key challenges that mergers and acquisitions face. This exposition contains both text and graphical information and representation of information regarding mergers and acquisition and it provides succinct but relevant analysis of mergers in the $21^{\text {st }}$ century.
\end{abstract}

Keywords: acquisitions, mergers, tax law, leverage, synergy, efficiency, growth

\section{Introduction}

Under the backdrop of economic globalization, enterprise internationalization is spreading around the globe. To bolster the international competitive state and initiate global business strategy, conglomerates are embracing large scale, far reaching cross-border mergers and acquisition wave. Through international mergers and acquisitions, multinational firms have prospects of bypassing barriers and investment risks in their home countries.

The $21^{\text {st }}$ century has been a time of intense mergers and acquisitions activities in both developed and developing nations. The mergers and acquisitions are a direct result of rapid growth of economies, economic globalization, and economic strategies initiated by governments that are keen on capitalizing on the potential of the international markets. From the annexation of IBM's personal computer division in 2004 to the announcement of the Lenovo Group, the global market is witnessing an increase in mergers and acquisitions.

It is not a secret that mergers grapple with sustenance and risk failure. According to a study conducted by KPMG, 83\% of the mergers do not bolster the returns of the shareholders. Historically, mergers have been known to suffer the two-thirds loss of value on their shares in the stock market (Bhringu \& Suri, 2011). The motivation behind mergers and acquisitions can be flawed. In many instances, there are delicate issues surrounding the attempts to make merged entities successful. Mergers are usually majorly driven by one common factor, which is fear. Globalization and technological developments have greatly influenced the global economic landscape due to their direct impact on the administrative decisions at the firm level. When a firm is merged or acquired, the decision is majorly based on a market fit or product, but differences among employees are normally ignored. It is a monumental mistake to assume that worker issues are easy to manage and overcome. CEOs who fail to look at the issue with the gravity desired may not like the eventual outcome of their inaction.

This paper looks at the changing human resource dynamics in merged and acquired firms and highlights the challenges that the merging and acquisition process brings to the performance of the new firm. The point of my paper is to understand that merging firms stand to gain greater benefits in terms of performance than the perceived personnel 
challenges to be encountered in the process. As such, mergers and acquisitions have a low cost to benefit ratio, which warrants its pursuit.

\section{Literature Review}

\subsection{History of Mergers}

It is interesting to look at the timeline of mergers and acquisitions over the last 100 years. Historians and economists primarily refer to merging and acquisition activities in six different waves. The first wave $(1897-1904)$ was also known horizontal combinations and consolidations of myriad industries that are dominated in the United States.

The second wave was from 1916 - 1929, and it involved mainly horizontal deals. However, vertical deals were also present among the US-dominated firms.

The third wave occurred between 1965 and 1969, and it was also known as the conglomerate era. This era involved the acquisition of firms in different sectors.

The fourth wave occurred between 1981 and 1989, during the era of corporate raiders financed by junk bonds.

The fifth wave occurred between 1992 and 2000 and involved large megamergers mainly in Asia and Europe.

The sixth wave from 2003 to date. These mergers are strategic in nature and are designed to complement firm strategy.

\subsection{Mergers and Growth}

An organization can achieve both internal and external growth. Internal growth can be attained if the organization expands its business operations or scales up its operations by initiating new units or entering novel markets. However, internal growth can be faced by myriad challenges such as the limited size of the prevailing market or obsolete product category or different restrictions from the government. Again, companies may not have specialized knowledge to gain entry into a new market or initiate a new production line. These engagements require time to establish, only then will the investor realize positive returns. In such situations, external mechanisms of expansion namely mergers and acquisitions, joint ventures, or takeovers may be used. Tambi (2005) provides an evaluation of mergers and acquisitions concerning the performance of a corporation. Although theoretical assumption sets the claim that there is an overall improvement in the performance of a company due to increased power in the market and the impacts of synergy, the dynamics of mergers and acquisitions go beyond such assumptions (Tambi, 2005).

In the United States, several mergers and acquisitions have been seen over the years with the underlying impetus of growth. Wall Street dealmakers show a record of growth for companies as some of the most recognizable names in corporate America take part in billion-dollar mergers and acquisitions. Previously, the American Airlines has announced a merger with the US Airways on a deal that is worth $\$ 11$ billion. On the other hand, Warren Buffett's Berkshire and private equity company 3G have also announced \$28 billion mutual acquisition of food conglomerate Heinz. These are just two merger and acquisition deals that follow closely upon the $\$ 20$ billion-plus buyout of Dell private equity company Silver Lake Partners and the founder of the firm, Michael Dell (Matthews, 2013).

\subsection{Reasons for Merging}

Among the chief reasons why firms may choose to merge is to ease financial constraints and to get the benefit of trained human resource capable of handling local challenges. According to KPMG report, the reasons can be grouped into growth, synergy, diversification, defensive measures, pressure to deal, and horizontal as well as vertical integration. Growth is usually linked with acquiring new consumers and getting more profit (Bhringu \& Suri, 2011). However, it can also be related to gaining access to brands, trademarks, facilities, patents, and employees. Synergy represents the potential ability of the merged companies to be more successful than the individual entities. It may translate into growth in income, cost minimization, financial synergies, and clearer governance. Diversification activities were predominantly significant in the third wave and used as a method of a corporate risk mitigation strategy. Horizontal and vertical integration involves the decisions made to achieve a dependable source of supply, lowering costs of supply, and abilities to demand specialized supply. Defensive measures concern the response to other mergers that intimidate the position of the firm. Finally, companies may merge because of the immense pressure on the management to reinvent earnings.

American conglomerates are known for mergers and acquisitions, and they do so mostly for growth in current or new markets. This is the case when an American consumer products company acquires an emerging market company that has established working synergies that can impact growth and margins. Through these, the value of the company is involved in the process of merging and acquisition. 
Firms in the United States have also been going for mergers and acquisitions because of the relative robustness of cash reserves in corporations. Interest rates are at the moment very low, and companies with huge capital can engage in deals through borrowing. Also, one cannot ignore the huge corporate balance sheets. While the demand for American goods remain tepid, as it has been in the European markets, companies are often motivated to grow through mergers and acquisitions. They consciously choose to steer clear of making huge capital investments on projects whose potential is untested (Wallstreet, 2015).

Coming down to one of the critical reasons that underlie mergers and acquisition, Lev and Mandelker (1972) argue that unless the parties are perfectly matched, the variances of combined effort will be smaller than the weighted average of the individual companies. The argument has since been named the diversification tenet of portfolio theory. This may not be accurate for perfect capital markets, but as studies reveal, there is no market that is fully efficient to mirror the actual picture. As such, there have been conclusions that state that mergers have no clear directional impact on the riskiness of the acquiring entities but also given the fact that financial leverage may be a good indicator of the stockholders' financial risk.

When opting for mergers and acquisition, management usually considers financial synergy and operating synergy in myriad ways. However, the ability to generate such synergy is an important issue. Kamal \& Bansal (2008) review claims regarding the achievement of synergy by mergers and acquisitions. The researchers do so by assessing the impact of mergers and acquisition on the financial performance of the long-term investments. This empirical study uses secondary financial information and tabulation. The findings show that in most cases, mergers and acquisitions have been able to generate synergy on the part of the acquiring company. The resultant company can have synergy in the form of more business, higher cash flow, cost cuttings, and diversification among many other aspects.

However, there are challenges that arise during the execution of these mergers in the form of communication, culture, and a few others. According to the KPMG report, $70 \%$ of mergers fail to generate tangible results to the shareholders. Further, more than half of the mergers destroy the real value of the mergers. Most of the firms report that their mergers and acquisition deals may be attributed to organizational and individual issues such as leadership issues, lack of mutual vision, and non-commitment from the part of the management. There could also be misaligned structures, poor change management, poor communication, and low levels of employee motivation. Personnel issues encountered in mergers and acquisitions can start at the initial stages of the process if planning and accountability is lacking. It is critical to fully involve all the stakeholders in the process to eliminate questions that may arise (Bhringu \& Suri, 2011). The firms must be aware of the major stages and milestones in the merging and acquisition process. This would enable the human resource to effectively assess the main pitfalls and plan how to effectively overcome them. Planning will help in minimizing the human capital risks. In the subsequent sections of this paper will elucidate these challenges in depth.

\section{Materials and Methods}

The core aim of this paper is to highlight the effects of mergers and acquisitions on employment, taking into consideration their assessable specific characteristics. This research will try to resolve the issue of diversity in acquisition probabilities. Data used in this assessment emanates from two major sources. The study uses Bureau van Dijk's database, which is the principal publisher of business information to assess dynamics of merged and acquired forms. It also uses data from the Library of Congress' Business Reference Services, which files all international deals touching on mergers, acquisitions, and joint ventures. This study covers a span of seven years, stretching from 2003 to 2010.

The financial service sector was selected because it has witnessed strong growth over the past decades. Secondly, it forms a solid case study for mergers and acquisitions in many countries around the world. The parameters assessed include profit margins, total assets, total costs, net profit, return on capital employed, interest cover times, current ratio, and advances.

To make a useful assessment of the data, this study excludes multiple takeovers through the years but include firms that have all the key information for the period set in the study. It also excludes firms that depict extreme outliers or those that have implausible figures. As such, this narrows the number of mergers and acquisitions assessed to 1,012, which is more manageable as compared to over 160,000 mergers and acquisitions that took place across Europe and the United States during the period 2003 to 2010. Key mergers that have taken place in the United States will be highlighted as well. Table 1 in the results section shows the firms included. 


\subsection{Mergers and Efficiency}

On the part of efficiency, the study finds supportive research evidence that the market takes into consideration the pre-merger bidder efficiency of the firm in adjusting the stock price of the entity at the announcement time. This is to suggest that the efficiency of the entity before a merger takes place has a significant positive impact on the creation of shareholder wealth at the time the merger is announced. Moreover, in reacting to the announcement, research on the market also perceives the prospect for future improvement of the firm's efficiency as an outcome of the prevailing event. Therefore, post-merger firm efficiency is ascertained to contribute to the value creation of the shareholder during the announcement of the merger. Specifically, this study investigates the research evidence that suggests a difference in returns on investment based on either post-merger profit efficiency or the normal of cost efficiency.

Specific assessment of the banking sector in European region shows that the pre-merger efficiencies of banks contribute to shareholder value creation in the short term. There is evidence that post-merger bank efficiency has a positive impact on the shareholder value creation at the time of the announcement, which is related more to the profit efficiency rather than the cost efficiency. Also, the research finds cumulative abnormal returns that are statistically significant.

Many banks sought to enter into mergers expecting to gain efficiency by lowering costs and increasing profits. They believed these actions would enhance their competitive position by facilitating cross-sale of products upon getting a large consumer base, and diversifying geographical risks. Efficiency gains have been noted by many merger studies as the major source of value creation (Houston and Ryngaert, 1994). They are removing coinciding functions and the streamlining of clandestine operations. In other terms, most often than not, post-merger gains are attained after implementing restructuring strategies aimed at realizing the cost-cutting and revenue enhancement objectives.

Previously, the entry of foreign banks into a region or country was normally attained at the expense of the hosting country's banks, small business, and sometimes the government. Competition with bigger banks was widely known to be costly to local banks as they normally lose their business with prevailing multinational companies, which prefer to deal with the multinationals. Small businesses may have grappled for lack of access to services given by foreign banks in a cheap and effective manner. Additionally, international banks tend to be less reactive to the wishes of local governments leading to the weakening of the local economy. According to Clessens, et al. (2001), international banks that find their way into the developing markets usually have greater profitability, higher interest margins, and greater outlook than domestically owned ones. Their findings depict a situation where a larger share of international banks in the country creates competition. This study further reports that the number of banks and their branches in these developing countries have a significant impact on competition than the market share they occupy. In Turkey, Pakistan, and Korea, European-based banks helped domestic projects achieve the opportunity to get access to capital overseas. As such, liberalization has been shown to spark growth in the financial sector and the prompt rise of competition in the banking field (Cho and Khatkhate, 1989).

According to Fritsch, et al. (2006), mergers and acquisitions in the European banking sector reached a high of 794 billion US dollars. Out of this figure, cross-border mergers and acquisition accounted for 203 billion US dollars. At that time, cross-border mergers and acquisitions rose from a quarter or $25 \%$ to $40 \%$ of the entire deals, and the number of mergers and acquisitions in the CEE nations involving Western European institutions grew from less than $1 \%$ in the 90s to more than $10 \%$ in 2005. In another report, documents on the number of institutions in Europe that have been in mergers and acquisitions grew from 9,800 to 8,700 units. The decline was largely because of domestic mergers that may have outnumbered international deals. According to Allen and Song (2005), out of around 500 deals involving financial institutions, 70\% involved domestic institutions. Increased consolidation locally appears to many researchers as an attempt by some countries to develop national champions that can outcompete at the global level (ECB, 2010).

The European Commission reports that within the European Union, the average number of cross-border mergers has been the same as domestic mergers and acquisitions. However, on the average, the international bidders are bigger than local acquirers. Experience shows that on average a credit institution is more likely to acquire the minority shares in an international deal than in a local merger. Another notable finding is that for some time, international consolidation took place majorly at the regional level within the European Union. For instance, 90 percent of the mergers and acquisitions that took place in the European Union involved the financial entities in the Nordic nations. This is also the situation in the Benelux region where the proportion is $60 \%$ (ECB, 2010). 


\subsection{Challenges of Mergers and Acquisitions}

\subsubsection{Poor Communication}

Mergers increase the financial power of the companies engaged in the process, which make them stronger to surmount the industry challenges. Since the number of players is reduced in the market when companies come together, the resultant company can redirect its resources as it rides on the successes of each other to make their efforts worthwhile under minimal effort. For instance, Schildbach (2008) found that the number of financial institutions in the EU-15 dropped to 6,926 from an initial figure of 9,624 representing a $28 \%$ fall in 2006 . Unsurprisingly, the banks' asset base grew by a whopping 12 percent per annum. This tremendous growth rate was more than triple the nominal GDP within the same period. The consolidation of the banking sector increased growth from 48.1 percent to 53.6 percent over a ten-year period from 1997 to 2006, (ECB, 2010).

According to Cybo-Ottone and Murgia ( 2000), mergers and acquisitions tend to favor international businesses. They note that even though the trend coincides with the other recent studies about this topic, it differs from the pioneering European study that investigated this topic. It is believed that the market will respond much better to a well-performing international merger that is seeking to gain entry into a local market than a local merger. The international mergers have the exposure and rely on local knowledge from their acquisition to excel in the local market. These postulations are limiting since there is no conclusive data to support them.

Mergers and acquisition face a myriad of challenges in the process of their implementation. Communication is one major tool that can lead to a disastrous end of a business if not used correctly in the process of merging companies or an acquisition. In fact, businesses have gone under due to poor communication during the process. BenQ failed to communicate the intentions to the employees when it acquired Siemens. The company did not have any prior knowledge in telecommunications and the acquired company collapsed leading to a major financial disaster for the company (Cheng \& Seeger, 2012). The employees felt betrayed since they were not involved in the process.

\subsubsection{Worker Apathy}

Poor communication can lead to apathy within the company. When employees willingly refuse to take responsibility at their place of work, the company is courting financial doom. Apathy arises mostly when the management of the company fails to inform the employees of its intention to merge with a formerly rival company or acquire a smaller rival company. They could be doing so due to the feeling that they may be rendered redundant in the process. They learn to distrust the company and their loyalty shifts.

Worker apathy is one of the biggest problems in a merger or an acquisition. According to Lee and Jiang (2014), workers want to feel a sense of belonging to a company and they need to feel appreciated. They need to know that their opinions are valued and respected. They should know that they are an important aspect of the company and not just another cog on the wheel. When the company owners fail to make their intentions known to the employees, they begin to understand that they are just another dispensable lot whose input does not matter. For that reason, they begin to abscond duty and develop a carefree attitude that could be detrimental to the company.

When the employees finally come to the realization that they are not an important resource to the company, they make sure that the management feels the effect of their absence by failing to cooperate with the management. They deliberately let things go wrong because they want the management to follow them around. They may even sabotage production, which could detrimentally affect the quality of the products coming from the production lines. On worst-cases scenario, they could come to work punctually and pretend to be very busy while in actual sense, they are doing nothing. They could even use that opportunity to leak business secrets to the competitors who could take advantage of the situation to lodge an onslaught on the company.

\subsubsection{Cultural Shock}

The announcement of Chrysler's merger with Daimler was referred to as a merger of equals. The merger was named a merger of equals because the two companies were in the same industry and they made similar products in an effective manner. However, the culture in Daimler was conservative while the culture in Chrysler was creative, diverse and dating. A fiasco was declared after the merger occurred. Different cultures of the two organizations had bother Chrysler and Daimler at war. The two companies were essentially different on every level including philosophies, formality, and operating styles. German culture became prevalent as Chrysler's culture was suppressed. The employees became increasingly dissatisfied such that the company was making colossal losses by the year 2000 (Li \& Jiang, 2014). 
Other than the differences in corporate cultures, there were trust issues. The employees of the two sides became reluctant in working with each other. The post-merger period was full of hitches and key executives from Chrysler resigned, and German counterparts replaced them. These two factors led to trouble as conflicting goals and orders ensued in different departments. German and American managers held different values, which directed and drove their work. The newly merged organization was headed on the opposing side from the beginning. Daimler imposed hierarchical approach in which the new organization should work. Such a situation did not inspire the employees at Chrysler and raised serious communication concerns (Li \& Jiang, 2014).

The poorly performing company then moved to replace the American CEO James Holden with a new German director Dieter Zetsche. Shortly after the appointment of the German director, the company started aggressive downsizing to mitigate the organization-wide losses. By the end of 2000, the organization had recorded 512 million dollars in losses, and the share/stock value plunged all the way to $\$ 40$ per share from a high of $\$ 108$. The synergies that were never anticipated saw the light of day, and the merger simply took the two companies into chaos. By 2007, Daimler had to sell Chrysler for 6 billion dollars (Li \& Jiang, 2014).

Organizational cultures differ from organization to organization. During a merger, employees from one company may find the culture at the workplace so appalling that they find it difficult to cooperate with their fellow employees and the management. Since they are not used to doing things differently, the culture shock that they get and the time it takes for them to adjust will lead to lost productivity and reduced efficiency. As a matter of fact, some of the best talents may opt to leave the new establishment due to this reason alone. Finding and replacing such a talent may be very costly in terms of time and money since they will have to be sourced and trained.

\subsubsection{Retention of Employees}

Retaining employees may seem very challenging in the process of M\&A. Usually, the mergers and acquisition have to deal with negative perception felt by the workers. The negative perception can arise from uncertainties of the prospective merger. It is not certain on the direction to take, the leadership style to implement, job security among a host of other communication challenges. Subsequently, this makes the employees lose trust in the organization and regard leadership betrayal in the management. However, it is important to keep low turnover of employees at this crucial moment. Low turnover will boost productivity and foster employee integration so that they can exchange skills and experiences that will enable them to execute their tasks efficiently. Furthermore, recruiting new employees can result in financial implications. Also, turnover of employee can lead to loss of customer relationships and knowledge, (Saad, \& Jedin, 2016).

On overall, merger and acquisition can cause several reactions in employees. This is because M\&A brings several changes in an organization that can either cause anxiety, stress, role conflict and the perceptions of not being regarded justly. These attitudes usually have adverse implication for the workers, especially their future in that organization. Consequently, the firm must remain objective in the execution of its mandates in order to regain or maintain the trust of employees. This will help the organization preserve the intellectual pool among the employees. In this regard, it is the responsibility of the management to regularly communicate with employees to create the sense of transparency and respond to any concerns they hold (Cheng \& Seeger, 2012).

The day to day business activities of an organization can be inevitably affected if the employees are lost during the process of acquisition. This has a "knock on effect down the hierarchical line" that demoralizes further the already compromised fraternity of employees (Ibid). Many companies deal with turnover issues immediately after a takeover or an acquisition due to the reasons that we have enumerated so far. Employee retention is a big headache for managers and CEOs, especially during mergers and acquisitions. It is not easy to lose dedicated staffs who have worked for a company for a very long time due to the structural changes that take place after mergers. Many employees feel that their jobs will be taken away due to task duplication. Exceptional talent may feel that they need to be appreciated more due to the increased responsibilities. When they fail to get what they want, they move on to another place to seek for better opportunities. They believe they will get a place where they will get the kind of an appreciation that they deserve.

It may take quite some time before the organization finally reduces the rate of turnover and come up with better structures aimed for attracting and retaining the best talent. In the meantime, employee retention remains a challenge that the management has to contend with and try to find an amicable solution.

\subsection{Cost-Benefit Analysis of Mergers and Acquisition}

Mergers and acquisition are a leeway for an organization that is currently undergoing financial woes to find a strong financial standing. It has been exploited by many struggling company to find additional sources of funding to expand their budgets and the market share. 
Companies may have a myriad of other reasons why they merge or acquire other companies. However, what remains fairly constant across the board includes the following reasons:

Firstly, companies may seek to grow their businesses by acquiring smaller units within their industries. Horizontal mergers are commonly exploited for the reason of increasing the market share. The larger company gets an increased market share by buying the smaller company and gains access to the customer base that is loyal to the brand of that smaller company. On the other hand, the smaller company gets the financial and/or technical capacity to increase inventory and sales by using the already existing machinery.

Secondly, mergers are an opportunity for diversification. Two unrelated companies that are operating in different industries come together to create a product/service offering that complements each other to create more value for the customer's money. As a result, their customers derive more value for the same amount of money. Since each of these companies is experts in their respective fields, they create superior products that surpasses the customer expectations.

The third factor that may necessitate a merger is the synergy that comes with the merge. Companies seek to complement their weaknesses by affiliating with companies that are known to be the leaders in that particular field to create better returns. They reduce the costs of operations and produce superior products at a reduced cost. This can enable them to reduce their product/service prices in the market and beat their competitors based on price and quality. On the same note, a business may reduce supply chain costs by buying off one or more of its suppliers and/or distributors. They will be able to reduce the margins that they were formerly adding to their operational costs.

Finally, one company may choose to merge with another company to eliminate the prospects of future competition. They will be able to buy an already existing market share and increase their authority in the local market. This acquisition of the local market share may come at a steep financial cost to the company and force the shareholders to concede some value. The company to be acquired is aware of the value they have and will use it to ask for a premium from the acquiring company. If the merger proves successful, the resultant company has the advantage of a large market share and functional machineries to increase revenues and profits.

\subsubsection{Company Valuation before a Merger}

To gauge the cost of a company, numerous ratios have been proposed to help in getting a commensurate value proposition for the target company during a merger process. The ratios may not be applicable in all situations; hence, the management must decide on each unique case scenario to identify the best ratio to use to get the accurate valuation for the company.

Depending on the nature of business that the company is engaged in, there may be many other factors to consider before settling on the right ratio to use. Overall, listed below are some of the common ratios used to evaluate the value of a company before an acquisition.

The company may decide to use comparative ratios such as price to earnings ratio or the company value to revenue ratio. In the former case, the company may choose to offer a multiple of the total company earnings as the proposition for the takeover value. The financial records and/or stock performance will provide a clear understanding on the value of the company before making such an offer. On the other hand, a company may decide to propose its acquisition value as a multiple of its revenues. Here, the value of the company in the industry plays a critical role since it will determine the sales revenues in the future.

Another valuation aspect employed by companies to evaluate the value of a merger is through the determination of the replacement cost of the existing competitor. Here, the company determines the cost of setting up a competitor of a similar size to take their competitor out of the market and then goes ahead to make a proposition to the target company to sell off the company or face a competitor of a similar size. Even though this may work, the valuation may not be very accurate since an established company spends so many resources on talent acquisition, organizational culture development and retention of exceptional human resources.

Finally, a company may decide to use the discounted cash flow method to evaluate the value of a company it intends to take over. Here, the future value of the company is projected and then discounted to the current value by checking the potential income and subtracting the depreciation value of the assets. Once a value is determined, the company then uses it to propose a takeover value to the target company by presenting its projected future value to the managers/owners of the target company.

It is important to ensure that the valuation is done correctly as it will have a great impact on the financial life of the resultant company. Even more critical is the need to ensure that the existing human resources are taken care of. They are key to the development of the merged unit due to their experience and local knowledge. 
Even though mergers and acquisitions present a myriad of challenges to the involved companies, the benefits enumerated under the reasons for merging have a potential to make substantial profits for the company in the long run. Human capital challenges are present in almost all cases of mergers. However, it is important to clearly understand that the challenges are not insurmountable. Culture differences present a key problem in the process but integration can solve the problem. The employees must learn to put aside their differences for the common good of the company. Above all else, communication must be done transparently to ensure that all the stakeholder opinions are considered.

\section{Discussion}

According to the findings of the study, it is evident that a dearth of much-needed information or lack of communication may cause distrust and uncertainty in the firm's working environment, which leads to lower productivity levels than before (Li \& Jiang, 2014). Communicating is a skill that comes naturally, and it can be one of the hardest skills to learn. When managing in any merging and acquisition, it is important to keep all employees from the two or more firms in perspective at all times. The employees need information on the integration process through various channels of communication including emails. The responsible people should be aware of the concerns, fears, and questions raised by workers and communicate the answers in a proactive manner. Adhering to this simple communication rules can lead to a successful merger.

The retention of employees can be a huge issue in mergers and acquisitions, and many see it as a threat. Inherently, most mergers and acquisitions processes have issues with retention of workers. This is attributed to the negative attitudes felt by the workforce as a result of the changes. In this regard, the organization can have a shaky future since proper structures for leadership are not in place to enforce critical factors of integrity at the workplace. The bulk of these problems occur as a result of poor communication within the organization. In essence, workers normally lose trust in the newly merged organization and feel that they have been betrayed by the leadership (Kummer, 2008). During this process, it is important to keep the turnover of employees low because continuity of business is important in ensuring the success of the merger (Kim \& Park, 2015). What is more, high employee turnover can lead to loss of knowledge and weakening of customer relationships.

Workers may have myriad reactions regarding the merger and acquisition. A merger introduces several organizational variations, which can either lead to anxiety, stress, feelings of unfair treatment, or role conflict. These feelings usually have grave implications for the employees and the future of the organization in general. Firms must work proactively to regain or maintain trust amongst employees to retain them and maintain the intellectual trust that they represent. Replacement or reduction strategies play a vital role in the integration of a merger and acquisition. It is up to the management of the parties to communicate to the employees in a continuous manner and ensure that there is transparency while addressing any concern.

Culture refers to the long-standing implicit mutual values, beliefs, and assumptions that impact the attitudes, behavior and meaning in a society or organization. It is hard for a merged organization to carry the culture of the two agencies that existed before the process of merging because the employees rarely replace their latent beliefs and values in the long run. In general, when mergers and acquisitions take place, they bring changes in the management strategies and practices, which can bear negative consequences on the people of the organization. A sudden change in these practices could cause panic within the organization.

It is important to conduct a pre-merger due diligence to prevent challenges associated with culture. Due diligence should focus on risks that are classified into six categories including people cost risk, talent risk, culture risk, regulatory risk, structure risk, and engagement risk. Some risks overlap depending on the scoping. Even more important is a culture survey that will enable the organizations to determine the norms that exist within the two organizations. Cultural influences have the power to cause far-reaching and broad consequences. For instance, decision making in an entity can be quite polarizing to the two sides due to the differences in leadership styles. One side could be consultative while the other dictatorial and the manner in which people relate could be based on either informal or formal relationships (Weber \& Tarba, 2012).

The results regarding cross-border mergers and domestic mergers and their returns correspond with findings from Schmautzer (2006) and Houston et al. (2001). Both these studies note that wealth creation amongst bidders is present, unlike many other studies. They theorize that the creation of wealth for bidders is based on the assumption that the bidder turns out to be more efficient. This poses serious integration, which may threaten profitability.

\section{Solutions}

For whatever reasons that lead to the creation of mergers and acquisitions, it is important to note that the developers take intangible factors into consideration. It may be hard to quantify the humanistic aspect to mergers, and they are 
usually overlooked. In a typical situation, CEOs and management of firms would overlook this aspect due to the notion that they can rehire managers and employees. However, in the long run, there are detrimental outcomes of the merged organization. The top management should develop cultural strategy because mergers will affect culture at the workplace. There are tools for measuring the overall cultural values, skills, and habits of the organization that can help in determining the impact on the organization. Through continuous feedback, managers can understand their employee's concerns and issues before they are a threat to the firm in the long term. By executing such as strategy, the merging company can comprehend where the differences are and engage with workers throughout the merging period to carry out a successful culture change.

Effective change management is one of the greatest solutions to the issues that may arise in a post-merger scenario. Through careful planning and flawless execution, newly merged companies may mitigate most of the risks that this study identifies with mergers. Change management after a merger takes place in three distinct levels namely: the organizational, team, and individual level. Companies may also go through a myriad of experiences that they need to be prepared for while getting into a merger. Beginning and ending are key features of mergers and acquisitions, and these are usually addressed well at team levels. Depending on the situation and the expected synergies, current structures may require readjustment. Changing management at the level of the individual concerns various employee emotional states that are associated with the various states and stages of the mergers and acquisitions.

It is advisable to have a devoted project organization structure in place to ensure that integration of activities will be well facilitated and expedited. Many of the organizations that enter into mergers normally deploy a three-layer project organization structure. Aspirations to conduct post-merger integration processes that are successful pose particular leadership challenges for the merging organizations. Leaders need to direct the merging companies in directions that will unlock potential synergies. In addition, leaders need to conduct an active part in ensuring that change management at the level of the organization is effective for the organization, teams within the organization, and the individual.

\section{Conclusion}

Mergers and acquisitions in this century have taken root in both developing and developed nations. The history of mergers goes way back over 100 years and has gone through 6 stages. As such, the $21^{\text {st }}$ century stands as the sixth stage of mergers and acquisition. Mergers and acquisitions are driven by the need for growth and the pressure on the CEOs to increase income and profits of their companies. Financially struggling companies' merge with other companies in the hope that they will generate more profits. However, it is not as easy as it sounds and there are myriad complexities involved. At times, mergers and acquisitions do not benefit stakeholders and some even destroy the value of companies. Challenges such as communication issues, differences in culture, and other human resource-related issues hinder mergers and acquisitions from realizing their full potential. There is a need for more proactive involvement of all workers in merging firms to ensure that the process is smooth and everyone is incorporated in the change. Market dynamics should also be understood and respected by the merging companies to avoid worst case scenarios.

\section{References}

Bhringu, J., \& Suri, N. (2011). Post merger people integration. KPMG, 1-28.

Cheng, S. S., \& Seeger, M. W. (2012). Cultural Differences and Communication Issues in International Mergers and Acquisitions: A Case Study of BenQ Debacle. International Journal of Business and Social Science, 3(3), 116-127.

Cybo-Ottone, A., Noia, C. D., \& Murgia, M. (2000). Recent Development in the Structure of Securities Markets. Brookings-Wharton Papers on Financial Services, 2000(1), 223-273. https://doi.org/10.1353/pfs.2000.0007

ECB. (2010). Mergers and acquisitions involving EU banking industry. European Union

Fries, S. \& Taci, A. (2005). 'Cost efficiency of banks in transition: evidence from 289 banks in15 post-communist countries'. Journal of Banking and Finance, 29(1), 55-81. https://doi.org/10.1016/j.jbankfin.2004.06.016

Fritsch, M. (2007) 'Long term effects of bank acquisitions in central and Eastern Europe'.

Garcia, G. G. H. (2009). Sovereignty versus Soundness: Cross-border/Interstate banking in the EU and the US: Similarities, differences and policy issues. Contemporary Economic Policy, 27(1), 109-129. https://doi.org/10.1111/j.1465-7287.2008.00121.x

Goddard, J., Molyneux, P., \& Wilson, J. (2004). Dynamics of growth and profitability in banking. Journal of Money, Credit and Banking, 36(6), 1069-1090. https://doi.org/10.1353/mcb.2005.0015 
IMAA. (2016, March 16). M\&A Statistics - Worldwide, Regions, Industries \& Countries. Retrieved November 18, 2016, from https://imaa-institute.org/statistics-mergers-acquisitions/

Kim, B. J., \& Park, S. C. (2015). Mergers and Acquisitions in the U.S. Insurance Industry, 1-23.

Kummer, C. (2008). Motivation and retention of key people in mergers and acquisitions. Strategic HR Review, 7(6), 5-10. https://doi.org/10.1108/14754390810906373

Li, Z. M., \& Jiang, J. J. (2014). Problems and Strategies of Cross-border Mergers and Acquisitions for Chinese Enterprises. Journal of Economic Perspectives, 3(1), 28-35. https://doi.org/10.15590/abcjar/2014/v3i1/53473

Mandelker, G., (1972). Risk and Return, Journal of Financial Economics, 1(4), 300-336.

Matthews, C. (2013). Mergers and Acquisitions Boom! Is This a Good Sign for the Economy? Time. Retrieved from http://business.time.com/2013/02/15/mergers-and-acquisitions-boom-is-this-a-good-sign-for-the-economy/

Saad, N. M. \& Jedin, M. H. (2016). Effective Relationship Engagement in the Post-integration of Mergers and Acquisitions. International Review of Management and Marketing, 6(S7), 231-241

Tambi, K. (2005). Impact of Mergers and Amalgamation on the. Development, 1-14.

Vasconcellos, G. M., \& Kish, R. J. (1998). Cross-border mergers and acquisitions: the European-US experience. Journal of Multinational Financial Management, $8(4), \quad 431-450$. https://doi.org/10.1016/S1042-444X(98)00041-3

Weber, Y., \& Tarba, S. Y. (2012). Mergers and acquisitions process: the use of corporate culture analysis. Cross Cultural Management: An International Journal, 19(3), 288-303. https://doi.org/10.1108/13527601211247053 